\title{
Friction and Wear of Graphite Fiber Composites
}

\author{
C. A. Berg, ${ }^{*}$ S. Batra, $* *$ and J. Tirosh*** \\ Institute for Basic Standards, National Bureau of Standards, Washington, D.C. 20234
}

(May 16, 1972)

\begin{abstract}
Friction and wear of two different types of graphite fiber composites were studied in a pin-disk sliding contact wear machine. Composites reinforced ( $62 \%$ by volume) with low modulus, high strength circular fiber (Modmor II) exhibited very high resistance to wear [a threshold wear load of $\sim 20 \mathrm{~N}$, a maximum bearing load of $\sim 50 \mathrm{~N}$, and a wear coefficient of $\left.\sim 10^{-6}\right]$ when worn by hardened steel pins. How ever, the composite produced extreme abrasion on the steel counterface. Composites reinforced $(62 \%$ by volume) with high modulus, lower strength, noncircular fiber (GY70) also exhibited high resistance to wear (a threshold wear load of $\sim 25 \mathrm{~N}$, a maximum bearing capacity of $\sim 20 \mathrm{~N}$, and a wear coefficient of $\sim 10^{-6}$ ) when worn by hardened steel, but these composites developed a surface film which prevented abrasional damage to the steel counterface.

Potential applications of the two different types of composites in bearings are discussed. The advantages of these composites in bearings subject to corrosion, vibration, loss of lubrication, or impact damage are noted.
\end{abstract}

Key words: Composites; friction; graphite fiber; wear.

\section{Introduction}

In recent years a number of different types of graphite fiber have been developed for use in advanced composite materials. Used in combination with polymeric matrices (epoxy, polyimid, etc.) these fibers produce very light (density, $\rho \sim 1800 \mathrm{~kg} / \mathrm{m}^{3}$ ) stiff (Young's modulus, $E \sim 2.8 \cdot 10^{11} \mathrm{~Pa} \sim 4 \cdot 10^{7} \mathrm{psi}$ ) and strong (tensile strength, $\left.\sim 7 \cdot 10^{8} \quad \mathrm{~Pa} \sim 10^{5} \quad \mathrm{psi}\right)^{1}$ materials which have attracted wide attention for possible application in lightweight high-performance structures such as airframes and space vehicle frames. However, in addition to their well-recognized potential in aerospace structures, graphite fiber-reinforced plastic composites appear to possess the low friction and high

\footnotetext{
* Professor and Chairman, Department of Mechanical Engineering, The University of Pittsburgh. Presently visiting scientist, Institute for Basic Standards, National Bureau of Standards, Gaithersburg, Md.

** Department of Mechanical Engineering, MIT, Cambridge, Mass.

*** Department of Mechanical Engineering, The Technion, Haifa, Israel.

${ }^{1}$ Properties quoted here are measured parallel to the fiber direction in unidirectional composites.
}

resistance to wear and corrosion required in certain bearing applications. In particular, bearings in which low density and high stiffness are required (e.g., rotating seals or bearings subject to vibration) appear to offer a promising area of application for graphite fiber composites.

The study of friction and wear of graphite fiber-reinforced plastics has attracted less attention than the study of stiffness, strength, and other mechanical properties related to structural requirements. There are several different fiber-making processes, using different precursor fibers and different conditions of graphitization, and yielding fibers of different intimate structure and different mechanical properties. The differences in intimate structure-and resultant mechanical properties - of these fibers strongly influence the friction and wear behavior of their composites.

Broadly speaking, graphite fibers may be classified as having either high strength $\left(\sim 2.8 \cdot 10^{9} \mathrm{~Pa} \sim 4 \cdot 10^{5}\right.$ psi) and low modulus $\left(E \sim 2.1 \times 10^{11} \mathrm{~Pa} \sim 3 \cdot 10^{7} \mathrm{psi}\right)$ or low strength $\left(\sim \nless .<\cdot 10^{9} \mathrm{~Pa} \sim 3 \cdot 10^{5}\right.$ psi) and high modulus $\left(E \geqslant 4.2 \cdot 10^{11} \mathrm{~Pa} \sim 6 \cdot 10^{7} \mathrm{psi}\right)$. The various fibers being manufactured commercially, via the 
original R.A.E. ${ }^{2}$ process, can be produced with either high modulus and low strength or low modulus and high strength. Typical examples of such fibers are Whittaker Corporation's Modmor $\mathrm{I}^{3}$ (high modulus, low strength) and Modmor II (low modulus, high strength). In addition to the variations of modulus and strength which may be obtained through suitable alterations of a given graphitization process, one may obtain substantial variations of the intimate structure of graphite fibers by using different precursor materials. Graphite fibers with very high modulus $\left(E \sim 6.9 \cdot 10^{11} \mathrm{~Pa}\right)$ can be produced with radically noncircular cross sections (e.g., Thornel 75 with its crenellated cross section and Celanese GY70 with its "dog bone" cross section). The noncircular cross section of these fibers reflects certain aspects of their intimate structure, and the friction and wear behavior of composites made from these fibers is radically different from that of fibers produced via the original R.A.E. process and having the characteristic circular cross section which results from that process.

Previous reports of friction and wear of graphite fiber-reinforced composites have concerned fibers produced by the original R.A.E. process, or a variant thereof. These reports include the work of Lancaster $[1],{ }^{4}$ Giltrow and Lancaster [2, 3], Harris and WynRoberts [4], and Scott et al. [5]. In the following we wish to report and to compare the observed friction and wear behavior of composites made from two widely different types of fibers. Experiments were conducted using Whittaker 5206 epoxy resin reinforced with Whittaker Modmor Type II fiber which is circular with an elastic modulus of $2 \cdot 10^{11} \mathrm{~Pa}$, and a tensile strength of $2.4 \cdot 10^{9} \mathrm{~Pa}$. In addition, experiments with composites made of Celanese GY70 fiber in Celanese R350A epoxy were conducted. This fiber has very high modulus $(E \geqslant$ $5.2 \cdot 10^{11} \mathrm{~Pa}$ ), lower strength (tensile strength $\sim 2.1 \cdot 10^{9}$ $\mathrm{Pa}$ ) and exhibits the most radical departure from circularity, having a "dog bone" shaped cross section. These two fibers represent the extremes in mechanical properties and intimate structure to be found among currently available graphite fibers. These materials are described more fully in a later section.

\section{Experimental Procedure}

Friction and wear was studied with a pin-disk ap-

\footnotetext{
${ }^{2}$ R.A.E. represents the British Royal Aircraft Establishment; see British Patent 1110791 (Apr. 24, 1968) "The Production of Carbon Fibers," W. Johnson, L. Philips, and W. Watt.

${ }^{3}$ Graphite fibers are produced by several different proprietary processes with resulting differences in properties. The fibers produced by the various methods can best be identified by their trade names. The trade names are used here for purposes of identification only, and this use does not constitute an endorsement or recommendation of the product.

${ }^{4}$ Figures in brackets indicate literature references at the end of this paper.
}

paratus, using a fully hardened (yield stress $\sim 2.4 \cdot 10^{9}$ Pa) $5.04 \mathrm{~mm}$ diameter AISI No. 52100 [6] steel pin with a hemispherical head to provide the sliding counterface on a unidirectional GFRP5 disk. The pin-disk apparatus permits simultaneous measurement of both friction and wear. A schematic diagram of the apparatus is shown in figure la, and a photograph of the apparatus actually used is shown in figure $1 \mathrm{~b}$. The circular wear track produced by this apparatus was approximately $8.5 \mathrm{~mm}$ in radius. A strip chart recorder (fig. $1 \mathrm{~b}$ ) was used to record the signal from the strain ring which measures the frictional force opposing sliding of the pin. The gearbox (fig. $1 \mathrm{~b}$ ) allows variation of the speed of the turntable from 0 to $1.3 \mathrm{rev} / \mathrm{s}$.

The experiments were conducted at controlled room temperature $\left(70^{\circ} \mathrm{F} \sim 21{ }^{\circ} \mathrm{C}\right)$ and relative humidity (65\%). The amount of material worn from the specimens was determined by periodic weighings. Since the weight loss during an experiment was typically of the order of tenths of a milligram, the specimens were permitted to rest undisturbed at ambient temperature and humidity for approximately 24 hours after being removed from the test apparatus in order that any moisture removed by frictional heating
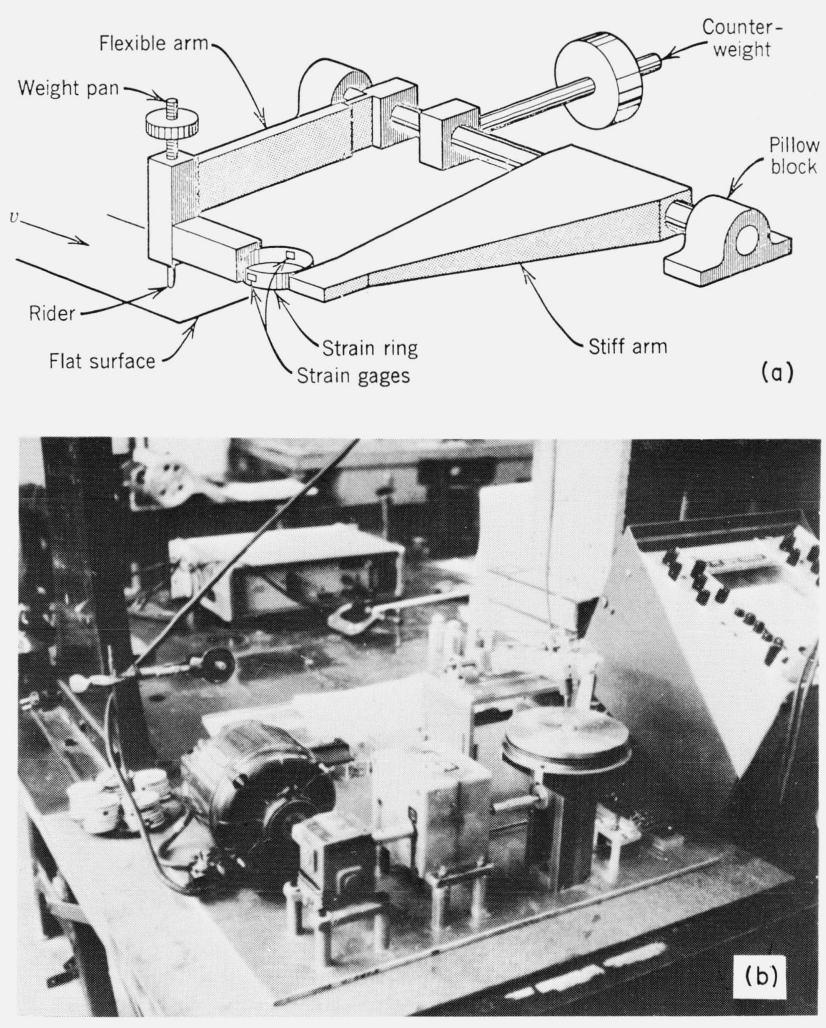

FigurE 1. (a) Drawing of the pin-disk wear testing apparatus; (b) photograph of the apparatus used in this study.

${ }^{5}$ The conventional abbreviation GFRP is used here for Graphite Fiber Reinforced Plastic. 
of the specimen would not introduce intolerable inaccuracies in the determination of the weight loss. ${ }^{6}$ In addition, og some specimens, wear rates were determined from the microsurface profiles of the wear tracks. ${ }^{7}$ The wear rates determined by the two methods agreed, in general, to within 10 percent. The wearing $\operatorname{load}(P)$ was applied by placing calibrated masses on the pedestal of the testing machine (fig. 1). The gearbox was set to provide the desired sliding speed, and then the turntable was set in motion. The frictional force opposing sliding was recorded on the strip chart as the specimen turned. The wear of the specimen was determined via periodic weighings; specimens were allowed to equilibrate with ambient humidity and temperature prior to weighing. After wearing, the surfaces of the specimens were examined with both optical microscopes and a scanning electron microscope to determine the character of wear mechanisms.

\section{Materials Studied}

Two different types of GFRP were studied:

Composite A: (Whittaker Modmor Type II, graphite fiber in Modulite 5206 epoxy resin.) The modulus of the Type II fiber is $2.4 \cdot 10^{11} \mathrm{~Pa}\left(35 \times 10^{6} \mathrm{psi}\right)$ and the tensile strength is $2.4 \cdot 10^{9} \mathrm{~Pa}(350 \mathrm{ksi}){ }^{8}$ The fiber content of the system was approximately 62 percent by volume. Flat plaques of the material with the fibers aligned unidirectionally were prepared by hot pressing several plies of prepreg tape, using the curing procedure (177 ${ }^{\circ} \mathrm{C}$ at $0.7 \mathrm{~m} \mathrm{~Pa}$ for $120 \mathrm{~min}$ ) recommended by the supplier. The fiber is circular.

Composite B: (Celanese GY70 graphite fiber in R350A epoxy resin.) The fiber modulus is $5.2 \cdot 10^{11} \mathrm{~Pa}$ $\left(75 \times 10^{6} \mathrm{psi}\right)$, and the tens le strength is $2.1 \cdot 10^{9} \mathrm{~Pa}$ (300 ksi). The fiber content of the system was approximately 62 percent by volume. The specimens were formed as flat plaques on caul plates in an autoclave at the Celanese Research Laboratories. The fiber has a flat "dog bone" cross section.

\section{Specimens}

Specimens of both types of composite were formed as flat plaques $25 \times 25 \times 4 \mathrm{~mm}$ with unidirectional fiber reinforcement running parallel to the plane of the plaque. Each specimen was lightly abraded by hand to

\footnotetext{
${ }_{6}$ The authors are grateful to Prof. E. Rabinowicz for pointing out this potential source of error at the out set of this investigation.

${ }^{7}$ The talysurf, an instrument which measures surface profiles, was used.

${ }^{8}$ Values supplied by the manufacturer.
}

remove the resin surface film remaining after hot forming. The specimen was then placed in the wear testing machine.

\section{Representation of Wear Data}

In dealing with the wear of metals in sliding contact it is possible to characterize wear by a dimensionless wear coefficient, $K$. The wear coefficient is dimensionless, is a useful design parameter, and offers a convenient means of comparing the wear behavior of different materials in specified ranges of operating conditions. For both the adhesive and abrasive wear of metals and plastics the wear coefficient, $K$, is given by

$$
K=\frac{\Delta V}{L} \cdot \frac{H}{P}, t+6
$$

where $\Delta V$ is the volume of the material removed, $L$ is the sliding distance, $P$ is the total contact load, and $H$ the hardness of the material being worn [7]. Experimental evidence indicates that the wear coefficient may depend upon the surface roughness, humidity, temperature, surface adsorbed layers and other environmental factors. Under a wide range of conditions encountered in practice the wear coefficient $(K)$ is constant and serves as a useful measure of wear for a given pair of materials.

Since it is not possible to assign an unambiguous hardness to the surface of a composite material the wear equation (1) cannot be directly applied. The authors would like, if possible, to retain the simple and useful notion of a wear constant to characterize GFRP wear; for this purpose some measure of effective hardness of the surface must be identified. The hardness of a metal surface may be regarded as the average stress required to produce large plastic strain under an indentor. A suitable generalization of hardness for a composite might be the local stress required to cause large irrecoverable strain of that phase of the composite which supports the wearing load. Since the graphite fiber itself appears to support the wear load (see descriptions of the wear surface below), the tensile strength $\left(\sigma_{u}\right)$ of the reinforcing fiber is proposed here as a measure of the hardness of the composite. The modified wear equation used here is

$$
\frac{\Delta V}{L}=K \frac{P}{\sigma_{u}} \cdot t+6
$$

One of the questions to be resolved in this study is whether (2) provides a meaningful characterization of 
wear of graphite fiber composites. For reasons discussed below it is concluded that (2) is useful for this purpose, within the range of bearing loads usually found in practice.

\section{Observations of Friction and Wear of Low Modulus, High Strength, Graphite Fiber Composites}

In a sequence of tests in which the wearing load $(P)$ varied from 9.8 to $49.0 \mathrm{~N}$, composites reinforced with low modulus, high strength fiber of circular cross section exhibited extremely high resistance to wear, and low friction. At a contact load of $29.4 \mathrm{~N}$ the wear coefficient ( $K$ of eq 2 ) was found to be $2.1 \cdot 10^{-7}$, while at a contact load of $49.0 \mathrm{~N}$ the wear coefficient was 2.1 . $10^{-6}$. Table 1 gives a summary of data obtained from these experiments.

At contact loads of 9.8 and $19.6 \mathrm{~N}$ the wear of the low modulus composite specimens was undetectable by weighing. Many metals exhibit a threshold wear load below which wear actually ceases. In the case of gold wearing on gold at room temperature this threshold load is of the order of $10^{-2} \mathrm{~N}$, while for steel on steel the threshold load is of the order of $10^{-3} \mathrm{~N}$ (see, e.g., Rabinowitz [7]). It is somewhat surprising to encounter a threshold wear load as large as $19.6 \mathrm{~N}$. However, the records of the sliding frictional force obtained during wear experiments at $9.8 \mathrm{~N}$ load show a highly repetitive pattern, which indicates that the fine structure of the surface does not change during the sliding process.
Figure 2 shows a set of records of sliding frictional force on the low modulus fiber composite, as a function of the angle of rotation of the specimen. The mark $\perp$ indicates that the direction of sliding is perpendicular to the fiber axis, and the mark $\|$ indicates sliding parallel to the fiber. The bottom record in figure 2 was taken after 26.5 hours of wearing $\left(9.5 \cdot 10^{4}\right.$ passes of the rider over the surface) the middle record was taken at 45.0 hours of wearing $\left(16.2 \cdot 10^{4}\right.$ passes $)$ and the top record at 96.0 hours $\left(34.6 \cdot 10^{4}\right.$ passes, and a total sliding distance of $24 \mathrm{~km})$. Note that the patterns of frictional force are not merely similar, but are congruent. Repetitive patterns

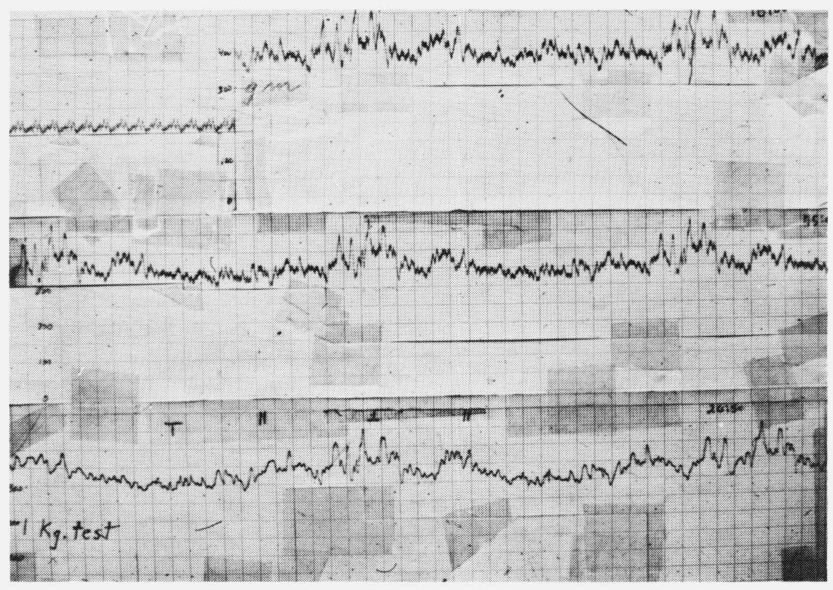

FigURE 2. Records of tangential frictional force opposing sliding on the low-modulus circular, fiber-reinforced surface; $\perp$ indicates the sliding direction was transverse to the fiber and $\|$ indicates sliding parallel to the fiber.

\begin{tabular}{|c|c|c|c|c|c|c|c|c|}
\hline \multirow[b]{2}{*}{ No. } & \multirow[b]{2}{*}{ Composite } & \multirow{2}{*}{$\begin{array}{l}\text { Contact } \\
\text { load }\end{array}$} & \multirow{2}{*}{$\begin{array}{c}\text { Fiber } \\
\text { tensile } \\
\text { strength }\end{array}$} & \multirow{2}{*}{$\begin{array}{l}\text { Av distance } \\
\text { of sliding }\end{array}$} & \multirow{2}{*}{$\begin{array}{l}\text { Sliding } \\
\text { speed }\end{array}$} & \multicolumn{2}{|c|}{$\begin{array}{c}\text { Wear coefficient } \\
\mathrm{K} \times 10^{-6}\end{array}$} & \multirow{2}{*}{$\begin{array}{l}\text { Wear of } \\
\text { rider }\end{array}$} \\
\hline & & & & & & by weighing & by talysurf & \\
\hline & & $\mathrm{N}$ & $\mathrm{Pa} \cdot 10^{9}$ & $\mathrm{~km}$ & $\mathrm{~mm} / \mathrm{s}$ & & & \\
\hline 1 & B & 2.45 & $\begin{array}{c}2.1 \\
(300 \mathrm{ksi})\end{array}$ & $83.3(1) *$ & 9.5 & \multicolumn{3}{|c|}{ wear could not be detected } \\
\hline 2 & B & 4.90 & $\begin{array}{c}2.1 \\
(300 \mathrm{ksi})\end{array}$ & $61.6(3)$ & 7.1 & $\begin{array}{l}1.0 \\
(0.7-1.4) * *\end{array}$ & 0.92 & not measurable \\
\hline 3 & B & 9.80 & $\begin{array}{c}2.1 \\
(300 \mathrm{ksi})\end{array}$ & $55.4(3)$ & 7.1 & $\begin{array}{c}0.94 \\
(0.3-1.8)\end{array}$ & $\begin{array}{c}1.1 \\
(0.3-2.3)\end{array}$ & not measurable \\
\hline 4 & B & 19.6 & $\begin{array}{c}2.1 \\
(300 \mathrm{ksi})\end{array}$ & $0.8(2)$ & 7.1 & $\begin{array}{c}1.0 \\
(0.8-1.2)\end{array}$ & - & not measurable \\
\hline 5 & A & 9.80 & $\begin{array}{c}2.4 \\
(350 \mathrm{ksi})\end{array}$ & $24.0(1)$ & 7.1 & wear could nc & be detected & severe \\
\hline 6 & A & 19.6 & $\begin{array}{c}2.4 \\
(350 \mathrm{ksi})\end{array}$ & $32.9(2)$ & 9.7 & wear could nc & be detected & severe \\
\hline 7 & A & 29.4 & $\begin{array}{c}2.4 \\
(350 \mathrm{ksi})\end{array}$ & $39.0(1)$ & 7.1 & 0.2 & - & severe \\
\hline 8 & A & 49.0 & $\begin{array}{c}2.4 \\
(350 \mathrm{ksi})\end{array}$ & $5.0(1)$ & 7.1 & 2.1 & - & severe \\
\hline
\end{tabular}

*Number in ( ) indicates number of tests.

**Numbers in ( ) indicate range of measured values. 
of sliding frictional force are commonly observed over short periods during sliding wear tests of metals. However, these patterns change gradually as wear of the specimen alters the fine structure of the wear surface. Evidently, the surface structure of the wear specimen from which the data of figure 2 are taken was not substantially altered by being subjected to $34.6 \cdot 10^{4}$ passes of a 52100 steel pin carrying a $9.8 \mathrm{~N}$ load. Thus, the surprisingly high threshold wear load of $9.8 \mathrm{~N}$, for low modulus, high strength, graphite fiber-epoxy composite by fully hardened 52100 steel, is indicated both by weighing and by indirect observation of surface detail.

High magnification micrographs of the wear surfaces produced on low modulus, high strength, graphite fiber composites reveal some of the reasons for the high wear threshold load and high resistance to wear of these materials. Figure 3 shows a typical view of the wear track on a specimen, at a point where the direction of sliding was perpendicular to the fiber direction. The specimen carried $9.8 \mathrm{~N}$ load for $24 \mathrm{~km}$. Note that the

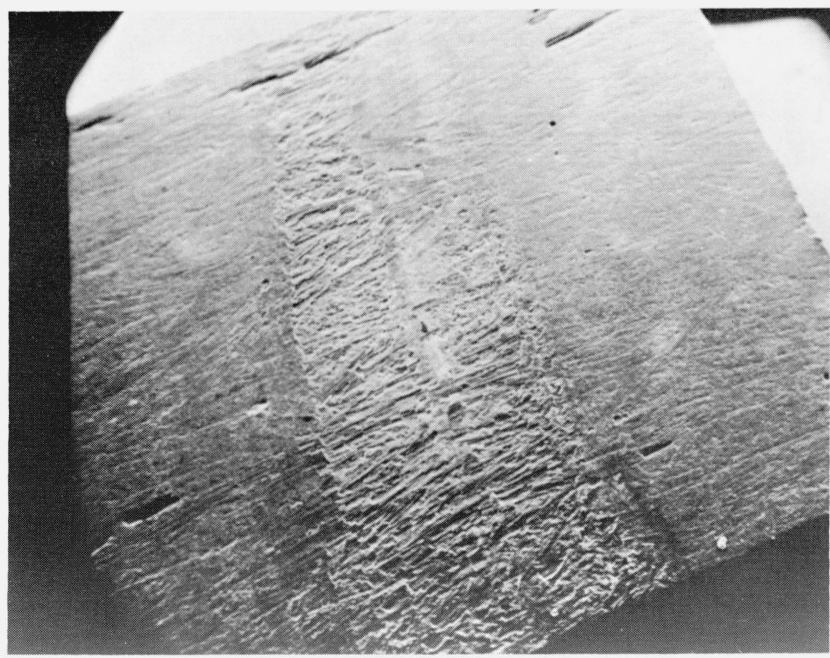

Figure 3. The wear surface of the low-modulus circular fiberreinforced surface.

fibers crossing the wear track are substantially intact, and that resin has been removed so that the fibers stand out in relief more boldly than on the unworn surface. Figure 4a shows a high magnification (SEM) micrograph of the wear surface on a specimen of the same material worn at $49.0 \mathrm{~N}$ load. Here, the fibers themselves still appear to be intact, but the matrix contains a number of cracks running both at the fibermatrix interface and through the interfibrile matrix cells. Figure $4 \mathrm{~b}$ shows several fibers on the same specimen ( $49.0 \mathrm{~N}$ load), which have been polished by the wear process, but which otherwise appear unaffected. In general, the wear surfaces produced on low modulus fiber reinforced specimens showed little, if any, evidence of adhesional wear-or of any other type of wear-occurring on individual fibers. Where wear was produced (at loads exceeding $19.6 \mathrm{~N}$ ) the chief mechanism of material removal appears to have been extension of systems of fatigue cracks in the matrix (fig. 4a), which eventually undercut whole groups of fibers and allowed bundles of fibers to be broken out of the surface of the specimen. The typical wear particles gathered from wear experiments with this material consist of large fragments of broken fibers, or a few fiber fragments still bonded together. Figure $4 \mathrm{c}$ shows one such fragment still situated on the wear surface of the specimen.

During the wear process the graphite fibers apparently support the wearing load. The graphite fibers presently under consideration are circular in cross section, and, according to the few reported studies of fiber intimate structure, the graphite basal plane is believed to be wrapped around the fiber axis. This being the case, whichever way one might rub a circular graphite fiber with a rider (along the fiber direction or transverse to it) the rider would slide on the graphite basal plane. Because of the high energy of bonding in the basal plane there would be little chance for the rider to remove a wear particle from an individual fiber by, e.g., adhesion. Thus, the fibers themselves would be highly wear resistant, and wear, if it is to take place, would occur on some scale comparable to or larger than the individual fiber diameter (e.g., whole fibers or fiber bundles must be broken out of the surface). Apparently the extremely high threshold wear load $(19.6 \mathrm{~N})$ found for the low modulus graphite fiber-reinforced material comes about because loads in excess of $19.6 \mathrm{~N}$ are required to extend the local fatigue cracking of the matrix over sufficiently large areas to produce the loosening and underc tting of fibers and fiber bundles.

Although the high wear resistance of the low modulus, high strength fibers of circular cross section offers encouraging indications of their potential as bearing materials, the effect of these materials on the 52100 steel sliding pin is severe. In fact, during the wear experiment at $9.8 \mathrm{~N}$ load, in which the composite underwent no measurable wear, the tip of the steel rider was worn flat. Figure 5 shows the worn tip of the rider in this experiment. In another experiment the clamps which hold the graphite fiber-reinforced specimen to the turntable came loose and the specimen fell off of the turntable. The 52100 steel rider, carrying $9.8 \mathrm{~N}$ load, then ran on the mild steel turntable for approximately 4 hours before the situation was discovered. During a previous run in excess of 4 hours under the same conditions the composite specimen exhibited no 

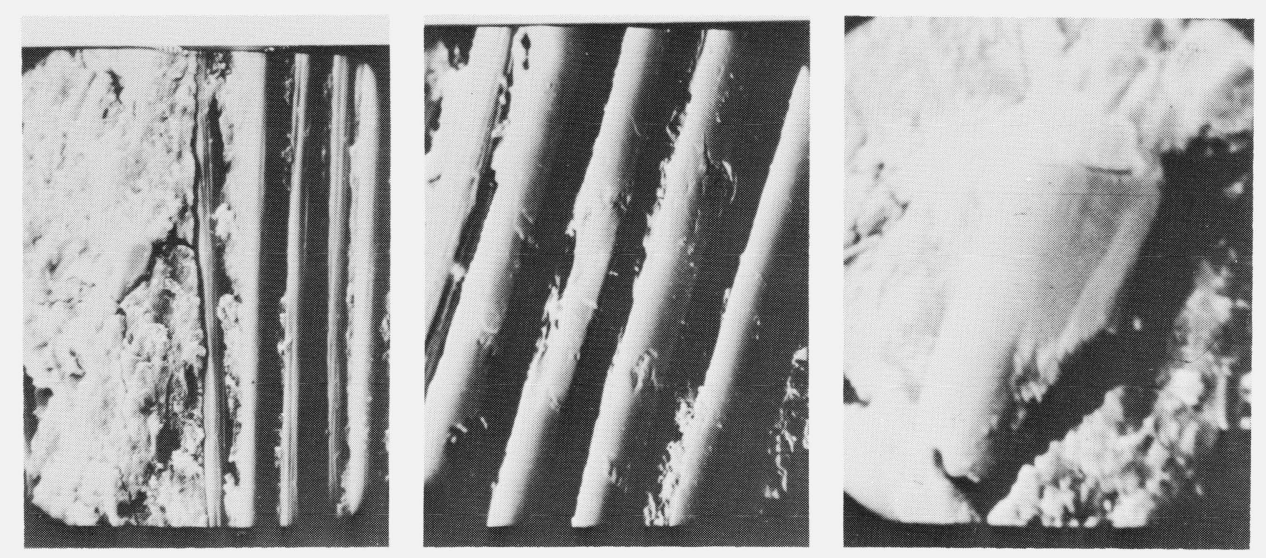

FIGURE 4. (a) Electron micrograph of wear surface on low-modulus fiber-reinforced material showing fatique racks in resin; (b) electron micrograph of same surface showing polished fibers; (c) electron micrograph showing a typical "wear particle," i.e., a broken fiber.

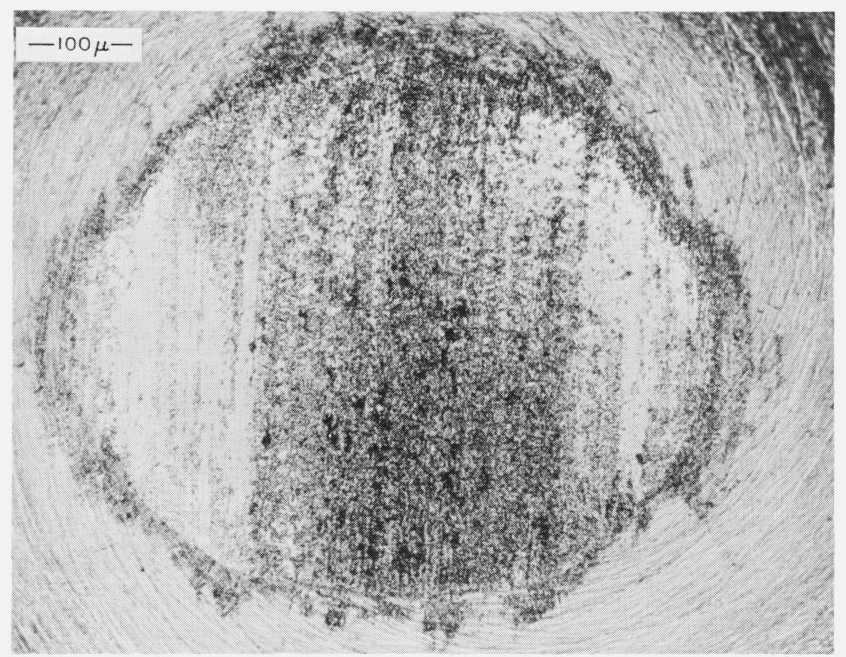

Figure 5. The worn 52100 steel rider tip after wearing on lowmodulus circular fiber-reinforced surface.

measurable wear; however, the steel turntable was severely worn by the 52100 steel rider in the (approximately 4-hour) period during which the specimen was missing. Figure 6 shows the groove which was worn in the turntable. While mild steel wearing against fully hardened 52100 steel is hardly a promising bearing combination, the fact that the composite material experienced no measurable wear under the same conditions which produced the severe wear shown in figure 6 does illustrate the extremely high wear resistance of the graphite fiber-reinforced epoxy composite. On the other hand, the severe wear which the 52100 steel rider experienced (fig. 5) while in contact with the low modulus, circular, graphite fiber-reinforced epoxy illustrates the extreme abrasiveness of this composite. Indeed, in order to take advantag of the high wear resistance of these composites one would have to select counterface materials with great care. The low modulus, circular, graphite fibers, since they exhibit little if any wear themselves, serve as extremely hard, abrasive, rodshaped particles of approximately $7 \mu \mathrm{m}$ diameter.

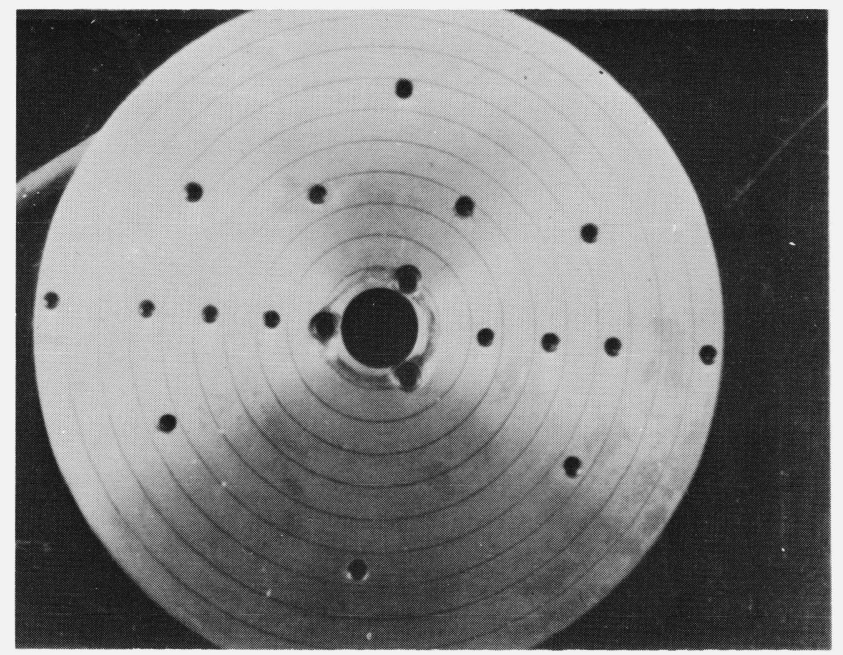

FiguRE 6. Groove which was worn into steel turntable after composite specimen fell off.

Survey experiments in which boron carbide tipped riders were used in place of the 52100 steel were carried out. Insofar as the wear of the composite itself was concerned the results were indistinguishable from those obtained with the steel riders. However, the boron carbide riders were sufficiently hard that they did not exhibit wear at loads up to 19.6 N. Experiments with boron carbide riders at loads greater than $19.6 \mathrm{~N}$ 
have not yet been carried out. In addition, some survey experiments in which both the rider and the plaque were made of composite material were carried out. The general tendency of the composite, both in the rider and the plaque, to resist wear at loads up to $19.6 \mathrm{~N}$, was seen also in these experiments. However, at present the total data from these experiments is sufficient for more than a preliminary report. The coefficient of sliding friction of the low modulus fiber composite sliding against 52100 steel was measured at sliding speeds of $45 \mathrm{~mm} / \mathrm{s}$ and $1065 \mathrm{~mm} / \mathrm{s}$, at $19.6 \mathrm{~N}$ load (table 2). The average coefficient of friction for the first condition was found to be 0.135 , with the range of data taken from several specimens extending from 0.13 to 0.14 . At the higher sliding speed the average coefficient of friction was found to be 0.145 , with the range of data extending from 0.13 to 0.16 . Thus a slight dependence of friction upon sliding speed is indicated, but has not been investigated further.

\section{Observations of Friction and Wear of High Modulus, Intermediate Strength, Graphite Fiber Composites}

The wear testing procedures described above were applied to specimens of high modulus, fiber-reinforced epoxy composites. These composites also exhibited high resistance to wear $\left(0.7<K \cdot 10^{6}<1.8\right)$ at contact loads ranging from 4.9 to $19.6 \mathrm{~N}$, when worn in contact with 52100 steel riders. At contact loads of $2.45 \mathrm{~N}$ and less, the high modulus material exhibited no measurable wear, as determined by periodic weighing. Figure 7 shows records of tangential friction force on the surface of the high modulus composite material under a wearing load $(P)$ of $2.45 \mathrm{~N}$. As in figure 2 , the congruency of these records during a wearing process extending from $9.4 \cdot 10^{4}$ passes to $74.7 \cdot 10^{4}$ passes of the rider over the surface indicates that the fine structure of the composite surface was not altered by the passage of the rider, and thus provides an indirect confirmation that $2.45 \mathrm{~N}$ is below the threshold wear load for the high modulus, graphite fiber-reinforced material.

During all of the wear experiments the wear rider itself exhibited no measurable wear. The surface of the tip of the rider showed a slight polishing, and under the

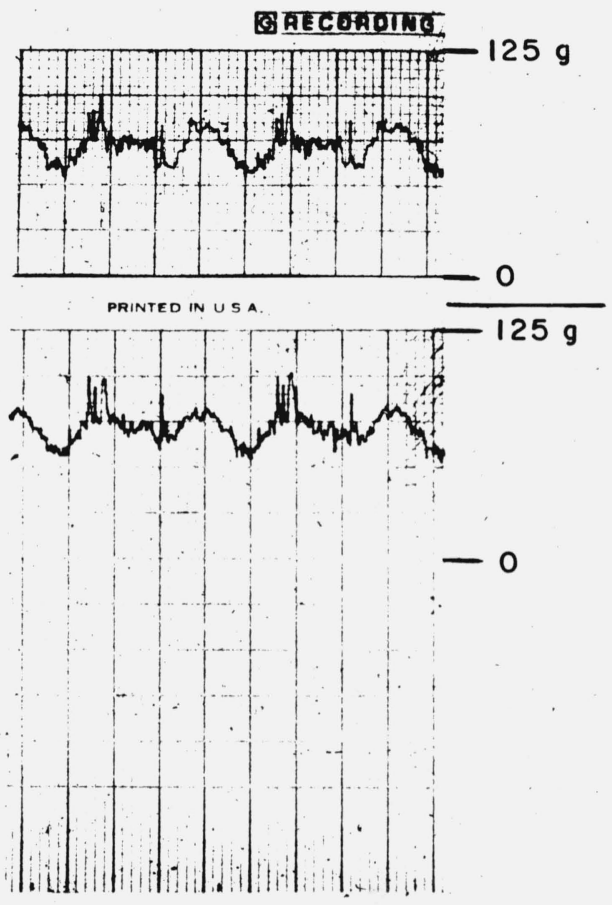

Figure 7. Records of frictional force on high-modulus noncircular (GY 70) fiber-reinforced surface.

\begin{tabular}{|c|c|c|c|c|c|c|c|}
\hline No. & Composite & $\begin{array}{c}\text { Contact } \\
\text { load }\end{array}$ & $\begin{array}{l}\text { S1iding } \\
\text { speed } \\
2.9 \mathrm{~mm} / \mathrm{s}\end{array}$ & $\begin{array}{l}\text { Sliding } \\
\text { speed } \\
70 \mathrm{~mm} / \mathrm{s}\end{array}$ & $\begin{array}{l}\text { Sliding } \\
\text { speed } \\
94 \mathrm{~mm} / \mathrm{s}\end{array}$ & $\begin{array}{l}\text { Sliding } \\
\text { speed } \\
4.5 \mathrm{~mm} / \mathrm{s}\end{array}$ & $\begin{array}{l}\text { S1iding } \\
\text { speed } \\
109 \mathrm{~mm} / \mathrm{s}\end{array}$ \\
\hline 1 & B & 2.45 & & & $0.14-0.19$ & & \\
\hline 2 & B & 4.90 & $\begin{array}{l}0.13-0.17 \\
0.10-0.19\end{array}$ & $\begin{array}{l}0.16-0.20 \\
0.16-0.28\end{array}$ & & & \\
\hline 3 & B & 9.80 & $\begin{array}{l}0.14-0.24 \\
0.12-0.15 \\
0.11-1.15\end{array}$ & $\begin{array}{l}0.17-0.28 \\
0.15-0.18 \\
0.15-0.17\end{array}$ & & & \\
\hline 4 & B & 19.6 & $\begin{array}{l}0.12-0.18 \\
0.13-0.19\end{array}$ & $\begin{array}{l}0.12-0.18 \\
0.14-0.21\end{array}$ & . & & \\
\hline 5 & A & 19.6 & & & & $0.13-0.14$ & $0.13-0.16$ \\
\hline
\end{tabular}


optical microscope tentative evidence of a transferred graphite film could be seen (fig. 8). ${ }^{9}$

It is important in judging the potential of the composite material in a bearing application, to bear in mind that the high modulus fiber reinforcement does not cause severe wear on the steel counterface. Figure 9 shows two steel riders, one worn flat after sliding on a low modulus graphite fiber-reinforced surface, and the other merely lightly polished by sliding on a high modu-

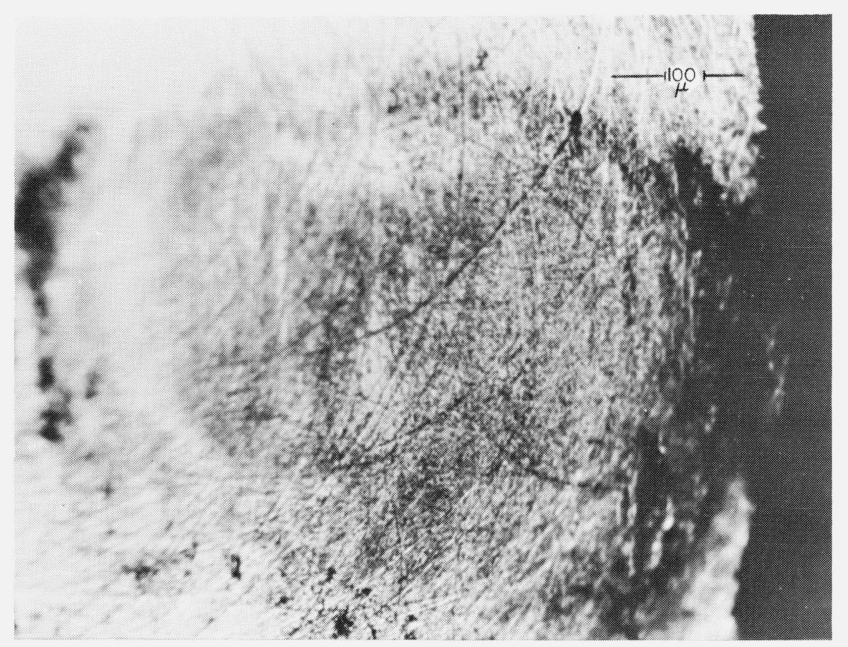

FIGURE 8. The tip of the 52100 steel rider after wearing against high-modulus noncircular fiber-reinforced surface.

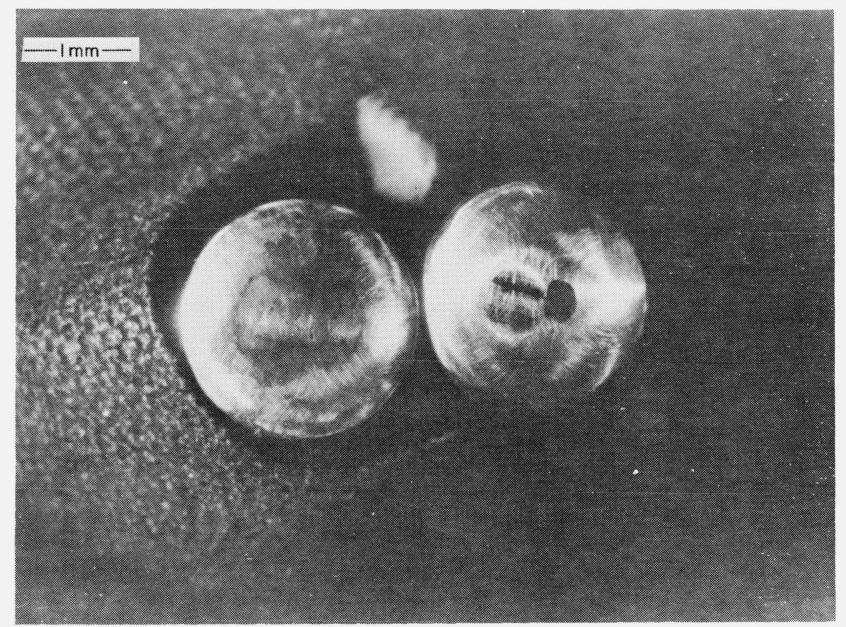

FIGURE 9. Two riders used in experiments. One worn flat by wearing against circular low-modulus fiber, the other only lightly polished by wearing against high-modulus noncircular fiber.

${ }^{9}$ The spectrographic data necessary to confirm the presence of a graphite film are not yet available.

${ }^{10}$ The reasons for the absence of wear on the steel rider, subject to sliding on the high modulus fiber reinforced surface are revealed through examination of the composite surface itself, and will be discussed below. lus graphite fiber-reinforced surface; both riders carried loads of $9.8 \mathrm{~N}$ for comparable distances of sliding $(25 \mathrm{~km}) .{ }^{10}$ When it was attempted to apply wearing loads of $29.4 \mathrm{~N}$ or more to the high modulus fiber-reinforced composite specimens, destruction of the surface of the specimen occurred at such a rapid rate that the "wear" of the material was too great to be of practical interest, and certainly could not be represented via the proposed wear constant of (2).

In summary, the high modulus, graphite fiber-reinforced material exhibited approximately the same high resistance to wear $\left(0.7<K .10^{6}<1.8\right)$ as low modulus fiber-reinforced materials, but has a somewhat lower bearing capacity $\left(\mathrm{P}_{\text {(threshold }} \sim 2.45 \quad \mathrm{~N}, \mathrm{P}_{(\max )} \sim 19.6\right.$ $\mathrm{N})$. On the other hand, the high modulus fiberreinforced material caused much less severe wear on the 52100 steel wear riders than did the low modulus fiber-reinforced material. Although the threshold wear load of the high modulus material is lower than that of the low modulus material, a threshold wear load of 2.45 $\mathrm{N}$ is still remarkably high as compared with threshold wear loads determined for metal-to-metal contact. With a permissible bearing load range of 0 to $19.6 \mathrm{~N}$ the high modulus graphite fiber-reinforced composite qualifies for many industrial bearing applications.

\section{The Wear Surface of High Modulus, Graphite-Reinforced Composites}

The most striking aspect of wear of high modulus graphite fiber-reinforced material was the complete dissimilarity of the wear surface from that found on low modulus fiber-reinforced material. Figure 10 shows a

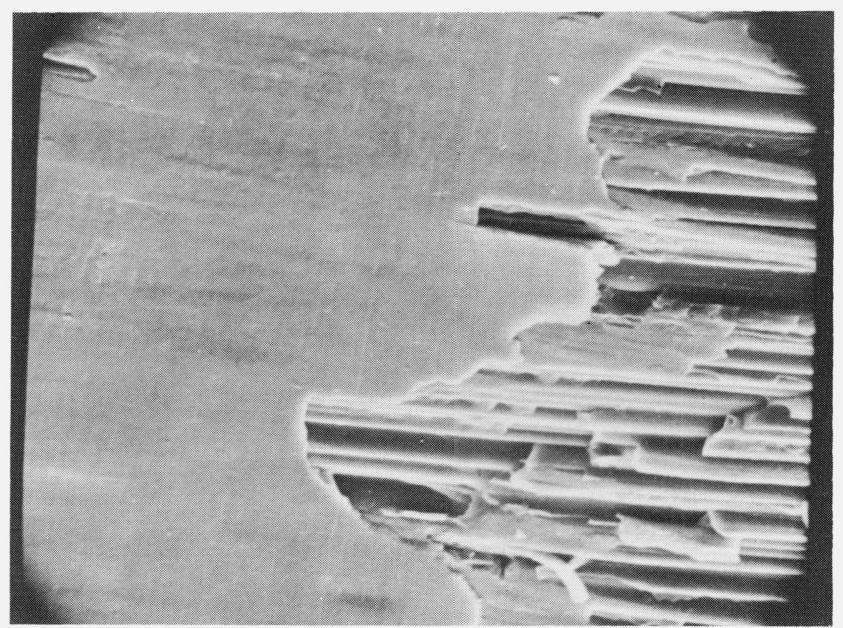

FIGURE 10. Electron micrograph of wear surface on composite reinforced with noncircular high-modulus (GY 70) fiber, after approximately $5 \mathrm{~km}$ sliding. Note buildup of film. 
scanning electron micrograph of the wear surface of high modulus fiber-reinforced material during the early stages of wearing ( $5 \mathrm{~km}$ total sliding distance) at $9.8 \mathrm{~N}$. As the micrograph indicates, a pasty, smooth film forms early in the wear process and covers the wear surface. This film is presently believed to be comprised of small graphite platelets which are broken off of the fibers during the wear process. Figure 11 shows the wear track of a specimen of high modulus fiber-reinforced material which was subjected to $10 \mathrm{~km}$ sliding under 19.6 $\mathrm{N}$ load. The individual fibers are only barely distinguishable, and the apparently smooth pasty film, typical of wear surfaces on this material, has complete-

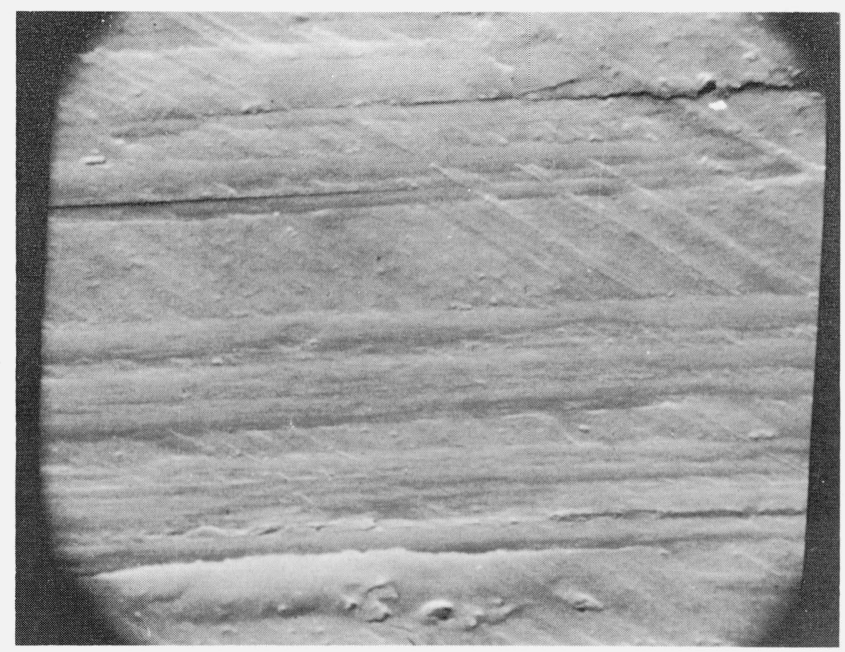

FigURE 11. Electron micrograph of wear surface on GY 70 reinforced composite after more than $10 \mathrm{~km}$ sliding. Note complete film cover.

ly covered the surface. Comparison of figures 11 and 4 provides an indication of the degree of dissimilarity of wear surfaces found on high modulus and low modulus graphite fiber-reinforced material. The smooth, pasty (apparently graphite) film is apparently responsible for preventing wear of the steel rider on material reinforced with the high modulus noncircular fiber studied here. If, as is presently supposed, the film does consist of small flakes of graphite, it is conceivable that the film itself could sustain large (average) shearing deformation by the sliding of graphite platelets over each other. In this case, the film would serve as a solid lubricant. The coefficient of friction measured on wear surfaces of high modulus graphite fiber-reinforced material are sufficiently small (see table 2 ) to be consistent with the presence of a solid lubricant film. If the filmlike wear surface of high modulus material is comprised of graphite platelets, broken off of individual fibers, then the capacity of the high modulus fibers to produce this film may be related to the cross-sectional shape of the fiber and the implied intimate structure. As a general rule, those few investigations of fiber intimate structure which have been reported (e.g., Johnson and Tyson; [8] Hugo and Philips, [9]) indicate that in most fibers the graphite basal plane tends to lie tangent to the surface of the fiber. One might assume that this general observation applies to both the Modmor II and the Celanese GY70 fibers. With the graphite basal plane lying tangent to the surface of the "dog bone" shaped Celanese GY70 fiber, the basal planes must be sharply bent around the ends of the dog bone, producing high energy sites where microfracture, and production of graphite microplatelets by contact loading with the wear rider, would be facilitated. The graphite basal plane might terminate at the ends of the dog bone, as is suggested in figure 12 . Since approximately half of the fibers in the wear surface are oriented so that the wear rider will strike the end of the dog bone, the proposed high energy sites or basal plane terminations in these ends should provide ample sources for production of graphite microplatelets via local exfoliation of graphite crystals. On the other hand, the low modulus fibers, having circular cross sections, would not offer such sites for film production.

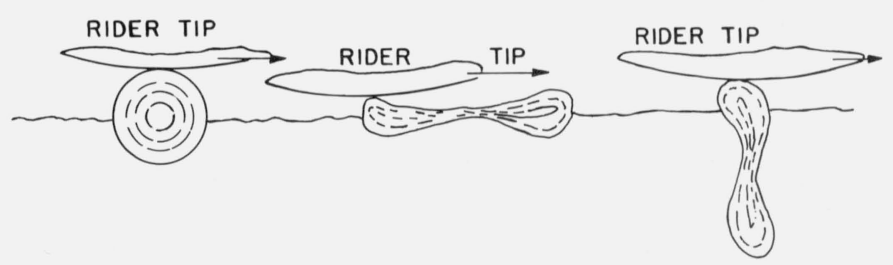

Figure 12. Circular fiber at left, with basal planes (- - -) wrapped around fiber axis, is relatively impervious to wearing by the Rider tip. "Dog bone" shaped fiber, center and right, has high-energy sites at ends which provide sources of graphite flakes for film formation.

The principal reason for the different cross-sectional geometry of the fibers studied here seems to be the nature of the precursor fiber, rather than the heat treatment which determines the modulus, strength, and extent of graphitization. As was pointed out above, the fibers studied here were chosen because they represent the extremes available in fiber modulus and cross section. However, high modulus fibers of circular cross section are available (e.g., Modmor I), and if the crosssectional geometry and related intimate structure of the fiber are responsible for film production, then composites made of these fibers should not yield lubricating films. In fact, in a survey experiment using a specimen of Modmor I (circular cross section) fiber-reinforced epoxy, subject to a wearing load of $19.6 \mathrm{~N}$ for a total sliding distance of $10 \mathrm{~km}$, the wear constant was found 
to be approximately $5 \cdot 10^{-7}$, high wear was observed on the 52100 steel rider, and no evidence of individual fiber destruction was found. The worn surface of the composite was essentially the same as that of the low modulus fiber composite. Thus, the fiber cross section, and the associated intimate structure, do appear to determine whether a surface lubricating film may develop during wear.

We have proposed that the surface film found on worn, high modulus, graphite fiber-reinforced material is comprised of graphite platelets, but we must add that at present there is no experimental evidence of the precise chemical nature of this film, and the proposal given here must be viewed as an hypothesis in need of testing. One aspect of film formation which must be considered is the mechanism by which the film at taches to the surface of the composite. There is, apparently, a rather strong bond between the compo ite substrate and the film, for the material removal rate during wear after the development of the film is extremely small, much smaller in fact than would occur were he wear surface merely covered with powdered graphite. Scanning electron micrographs employing backscattered primary electrons which provide somewhat greater surface detail on polymeric composite specimens, indicate that the surface film which appears smooth when viewed via conventional secondary electron emission may, in fact, be rather porous (fig. 13). It has been suggested that with the coefficient of friction observed in these experiments local heating may play a part in the film formation seen on the GY70-
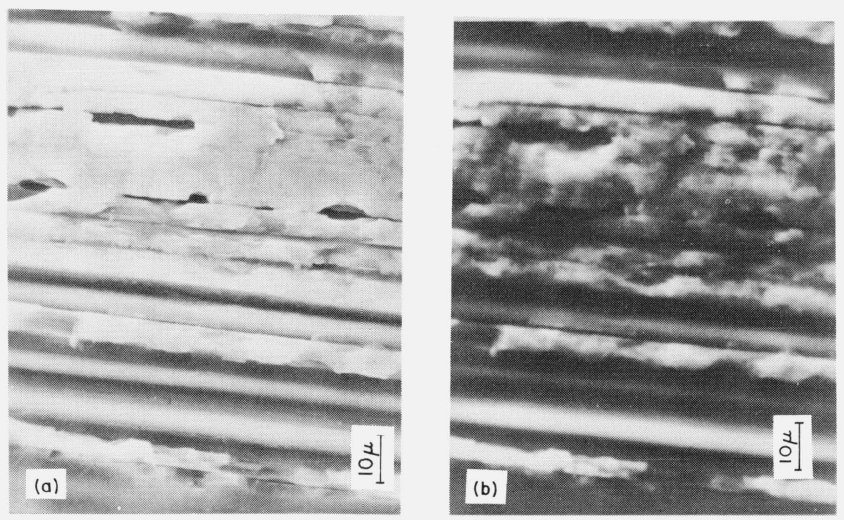

Figure 13. (a) Scanning electron micrograph, via secondary electrons of GY 70 worn surface. Surface appears smooth; (b) scanning electron micrograph, via back scattered primary electrons, of GY 70 worn surface. Surface shows porosity.
R 350A composite; it has further been suggested that different effects of local heating on the different epoxy resins used in the two composites may be partly responsible for the different characters of the wear surfaces observed $n$ these experiments. Further work is required to determine the nature and precise source of the film. With present evidence one can only offer the mechanism of film formation given above as a tentative proposal. However, one can say with certainty that the formation of the surface film on high modulus dog-bone shaped graphite fiber composites is accompanied by cessation of wear of the counterface, and this fact may bear importantly on future application of the high modulus material.

\section{The Wearing-In Phenomenon with High Modulus Noncircular Fibers}

An experiment with a total length of slide of $100 \mathrm{~km}$ was carried out using a specimen of the high modulus composite under contact with a 52100 steel rider carrying a load of $19.6 \mathrm{~N}$. The incremental wear determined via periodic weighing of the specimen was used to calculate an incremental wear constant $\mathrm{Kinc}$. Figure 14 gives the measured incremental wear constant as a function of the total length of slide $(L)$ during the experiment. The wear rate is extremely high at the outset of sliding $\left(\sim 10^{-4}\right)$, but within the first $5 \mathrm{~km}$ of sliding $\left(\sim 10^{5}\right.$ passes over the surface) the wear rate decreases rapidly to the level of practical interest for bearing ap-

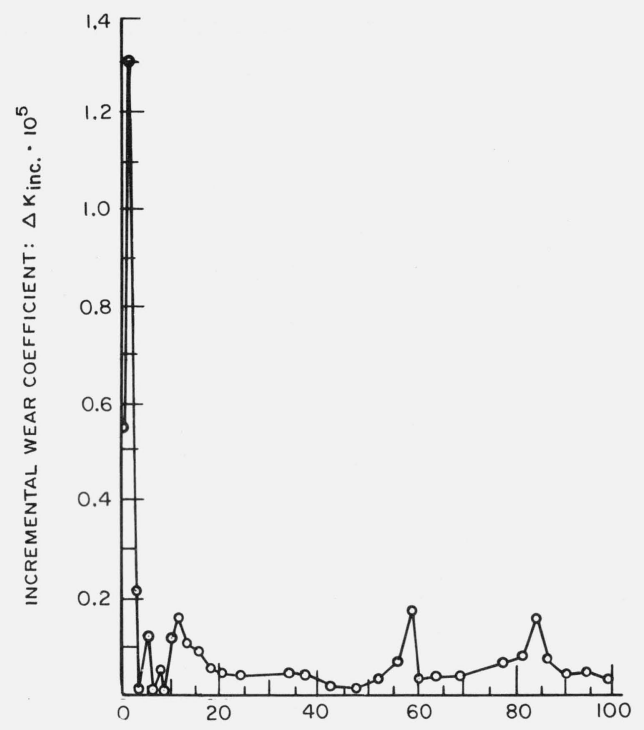

FigURE 14. Incremental wear coefficient measured in long duration $(100 \mathrm{~km})$ experiment with high-modulus fiber-reinforced material. 
plication $\left(\sim 10^{-6}\right)$. Thereafter, the wear rate oscillates regularly $\left(10^{-7}<\right.$ Kinc $\left.<10^{-6}\right)$, with a period of approximately $25 \mathrm{~km}$ sliding distance per cycle. The mechanism responsible for the cyclic wear rate indicated by the data of figure 14 is not presently understood. However, the total volume of material worn off of the surface (the area under each cycle in fig. 14) is approximately the same. This suggests that some basic structural unit on the surface (perhaps one layer of fiber) is destroyed during each cycle. The source of oscillating wear is yet another open question in the present state of understanding of wear of composite.

The data of figure 14 show a very strong "wearing-in" phenomenon, similar to that found in cast-iron bearings. Surface "preparation" occurs during the first $10^{4}$ passes of the rider over the high modulus fiber-reinforced surface. Thus, in design of bearing parts from this material, one must provide for an adequate "wearing-in" period to obtain optimum performance in service. Also, one must take the removal of material during the wearing-in procedure into account, both with respect to the production of wear particles and with respect to the alteration of tolerances of bearing. Moreover, wear testing procedures employed to evaluate this material for long-life service must be sufficiently long to pass through the initial domain of high wear rate.

\section{Characterization of Wear Via the Wear Constant}

The definition of the wear constant (2) implies that the rate of removal of material by wear is independent of the length of slide and is proportional to the applied load. According to the data upon which this report is based (e.g., fig. 14) the wear rate may be treated as if it were independent of the length of slide, provided that one considers sufficiently long periods to include several of the "cycles" shown in figure 14, and provided that one recognizes the "wearing-in" phenomenon seen with high modulus noncircular fiber. Moreover, the data of table 2 show that the wear rate, as represented by the wear constant, is a rather weak function of applied load in the domain between the threshold wear load and the maximum bearing capacity (19.6 to $49.0 \mathrm{~N}$ for circular low modulus fiber, 4.90 to 19.6 $\mathrm{N}$ for the noncircular high modulus fiber). Thus, the use of the wear constant to characterize wear rates of the composites studied here appears justifiable. For those who prefer to express the wear rate in (say) $\mathrm{cm}^{3} / \mathrm{m}$, the fiber properties given above along with the reported wear constant may be inserted into (2).

\section{Potential Applications}

The possibility of using graphite fiber-reinforced epoxy as a bearing material in a number of industrial applications suggests itself. For example, journal bearings where sliding contact may occur upon the breakdown of a lubricating system, and bearings in which dry frictional sliding must be contemplated (e.g., engine seals, air bearings and other seals subject to vibration, machine ways) appear as promising areas of application for this material. In such applications the high modulus, noncircular fiber reinforcement would have the advantage of producing low or vanishing wear on a steel counterface, while both of the graphite fiber materials surveyed here would have the advantage of being highly wear resistant themselves and being capable of supporting substantial bearing loads. Of course, if one were able to replace steel bearing counterfaces with material of sufficient hardness (e.g., boron carbide) for use with the low modulus, circular fiber-reinforced material, one could also obtain low or vanishing counterface wear rates, but at substantially greater ex pense.

A possibly outstanding advantage of using graphite fiber-reinforced materials in bearing applications is the low cost of fabrication and repair. For example, one might provide an extremely wear resistant machine way by cementing a tape of graphite fiber-reinforced material on the machine. Such an operation can be completed at ordinary room conditions. The wear resistant surface of the way could be ground to provide the desired flatness. But since the tape would be applied on an already prepared metal surface, only minimal grinding of the composite surface would be required to complete preparation of the way. Grinding operations with alumina or silica wheels provide a means of preparing such a surface. ${ }^{11}$ Once the surface were installed, it would provide an extremely wear resistant bearing surface without embrittling the machine way. If the composite surface were to be accidentally damaged (by, say, a sharp heavy object being dropped on it) the composite could be stripped off and replaced easily and cheaply. These same considerations would, of course, apply to the manufacture and maintenance of many other types of bearing surfaces. Finally, although the subject is not discussed here, it is appropriate to note that the extreme insusceptibility of graphite fiber-reinforced epoxy to environmental attack in atmospheres which are normally hostile to metals

"Studies of grinding and machining both types of GFRP reported on here have been con ducted and will be reported in a later writing. These extremely wear resistant composites are surprisingly easy to grind. 
(e.g., hot acids, salt water) suggests the possibility of using these materials to circumvent problems of corrosion wear, corrosion fretting, etc.

The extreme hardness of the low modulus, circular fiber reinforcement, and the severe wear it produces upon 52100 steel, suggest that this composite may be useful in polishing or cutting of hard metals. The use of graphite fiber-reinforced cutting and polishing wheels appears to merit further investigation.

\section{Conclusion}

Friction and wear of two different types of graphite fiber-reinforced epoxy were studied. Specimens with low modulus, circular fiber reinforcement and high modulus noncircular reinforcement were used. It was found that both materials, when worn against fully hardened 52100 steel, exhibited low coefficients of friction $(\sim 0.1$ to 0.2$)$ and very high resistance to wear. A wear constant, defined in such a way that the tensile strength of the fiber serves as a measure of surface hardness, was found to provide a useful characterization of composite wear. Epoxy reinforced with low modulus, circular, graphite fiber exhibited a threshold wear load of $19.6 \mathrm{~N}$, a maximum bearing capacity of $49.0 \mathrm{~N}$ and between these load limits, a wear coefficient of approximately $0.23 \times 10^{-6}$. The 52100 steel rider, when used against the noncircular fiber reinforcement, exhibited no wear at all. The surface of the noncircular fiber-reinforced material developed a film, presumably of graphite platelets, which was tightly adhered to the composite substrate. The film inhibited further wear of the composite and prevented wear of the steel counterface. A very strong "wearing-in" phenomenon occurred with the high modulus, noncircular, fiber reinforcement, approximately $10^{4}$ passes over the surface, at 19.6 $\mathrm{N}$ applied load on the rider, were required to pass through the initial transient period of high wear rate and reach the steady state condition in which the wear coefficient oscillated between $10^{-6}$ and $10^{-7}$.

Certain bearing applications of these materials appear promising, including antifriction bearings, machine ways, safety liners for journal bearings in which loss of lubrication might occur, and anticorrosion bearings. Cutting tool applications of the low modulus circular fiber are also discussed. Further investigation of the mechanisms of film generation and attachment with the noncircular fiber, the mechanism of wear with this material, and the behavior of both materials as anticorrosion bearings are recommended.

The authors are pleased to acknowledge the assistance provided by Mr. Wm. Corwin and Mr. David Davis in conducting experiments. In addition, data provided by Mr. S. Smith (in particular, data of fig. 14) and by Mr. Wm. Hauser (in particular, fig. 6) are most gratefully acknowledged. The financial support of the MIT Center for Materials Science and Engineering and the Celanese Research Company of Summit, N.J. made the work reported here possible; in addition, preparation of this paper was supported in part by the National $\mathrm{Bu}$ reau of Standards. This support is most gratefully acknowledged.

\section{References}

[1] Lancaster, J. K., The Effect of Carbon Fiber Reinforcement on the Friction and Wear of Polymers, Brit. J. Appl. Phys. (J. Phys. D), Ser. 3, 1, 549 (1968).

[2] Giltrow, J. P., and Lancaster, J. K., Carbon Fiber Reinforced Polymers as Self-Lubricating Materials, 6th Tribology Group Convention 1968, Inst. of Mech. Engineers, Proceedings Vol. 182, part 3N, Paper 18, (1967-68).

[3] Giltrow, J. P., and Lancaster, J. K., The Probe of the Counterface in the Friction and Wear of Carbon Fiber Reinforced Thermosetting Resins, Wear 16, 359-374 (1970).

[4] Harris, C. L., and W yn-Roberts, D., Wear of Carbon Fiber Reinforced Polymers in a High Vacuum Environment, Nature, Vol. 217, 981 (Mar. 9, 1968).

[5] Scott, D., Blackwell, J., McCullough, P. S., and Mills, G. H., Composite Material for Rolling Bearing Cages, Wear 15, 257269 (1970).

[6] ASTM A295, Specifications for Carbon Chromium Ball and Roller Bearing Steel, ASTM, Phila., Pa., (1972).

[7] Rabinowicz, E., Friction and Wear of Materials, John Wiley and Sons, Inc., N.Y., N.Y., (1965).

[8] Johnson, D. J., and Tyson, C. N., Low Angle X-ray Diffraction and Structure and Physical Properties of Carbon Fibers, J. Phys. (Brit.); D:Appl. Phys. 3, 526 (1970).

[9] Hugo, J. A., Phillips, V. A., and Roberts, B. W., Intimate Structure of High Modulus Carbon Fibers, Nature, Vol. 226, 144 (April 1970).

(Paper 76C1\&2-331) 